\title{
Medical Ethics: Context Is the Key Word
}

\author{
John Myers \\ Wellspring's Universal Environment P/L, Melbourne, Australia \\ Email: rebdoc1@bigpond.net.au
}

Received 23 June 2014; revised 22 July 2014; accepted 21 August 2014

Copyright (C) 2014 by author and Scientific Research Publishing Inc.

This work is licensed under the Creative Commons Attribution International License (CC BY). http://creativecommons.org/licenses/by/4.0/

(c) (i) Open Access

\begin{abstract}
Medical Ethics is no different to Ethics, but relates specifically to the doctor-patient relationship. This relationship is based on mutual trust-trust in the doctor's expertise and knowledge and trust that the patient is consulting the doctor, for his/her/their own health, wellbeing and welfare, without agenda or bias. In other words, the basis of the doctor-patient relationship is one of mutual trust and confidence. Thus, what is imparted between them is held in the strictest confidence. The doctor must act within the law. No third party influence can be brought to bear on this relationship without the patient's consent. In the case of minors the relationship is between the child's guardians as well as the doctor who must act within the law. In the category of "elderly" or adult guardianship or advocacy, those appointed and in positions of trust must take the person's wishes into account if the patient has capacity to make decisions or has indicated their wish prior to any such appointment. Capacity is defined as consistent belief or wish, awareness of what one does not wish for, satisfaction when wishes are respected and fulfilled and the opposite when they are not. Ethical practice is determined by taking context into account in decision-making and ensuring the sanctity of the patient's rights and wishes. Abuse is just the opposite, where actions taken or not taken are against a person's wishes. Personal wish determines best interest. Best interest may also be defined in terms of social functioning and psychological wellbeing. Discussion of ethics in terms of General Systems Theory is also addressed, and affects an action on the environment or others, i.e. ethics in the wider medical context may pertain if the person has a contagious disease and a period of quarantine or "isolation" or barrier" nursing is required, and where precedent is given to society's best interest over the person's wishes, as part of an educational process and as required for strategic disease management.
\end{abstract}

\section{Keywords}

Medical Ethics and Context, Rights, Behaviour and Abuse

\section{Introduction}

According to the Oxford English dictionary, accessed 12 June 2014 on the internet, using Google search, it says

How to cite this paper: Myers, J. (2014) Medical Ethics: Context Is the Key Word. International Journal of Clinical Medicine, 5, 1030-1045. http://dx.doi.org/10.4236/ijcm.2014.516134 
as follows:

\section{Ethics is defined as noun:}

"1. [usually treated as plural] Moral principles that govern a person's behaviour or the conducting of an activity: medical ethics also enter into the question.

2. [usually treated as singular] The branch of knowledge that deals with moral principles: neither metaphysics nor ethics is the home of religion.

Schools of ethics in Western philosophy can be divided, very roughly, into three sorts. The first, drawing on the work of Aristotle, holds that the virtues (such as justice, charity, and generosity) are dispositions to act in ways that benefit both the person possessing them and that person's society. The second, defended particularly by Kant, makes the concept of duty central to morality: humans are bound, from a knowledge of their duty as rational beings, to obey the categorical imperative to respect other rational beings. Thirdly, utilitarianism asserts that the guiding principle of conduct should be the greatest happiness or benefit of the greatest number."

Each of these, particularly the Aristotelian view and that of Kant, defines that morality is determined by effect on another or on others. The utilitarian view permits a minority to suffer at the expense of the majority—or what most will find satisfactory or happiness from but others won't or may not. Without reasonable undertakings or safeguards, the latter, in my view, is not ethical.

\section{Historical Landmarks}

Although ethics was practised by the patriarchs and matriarchs, it was the giving of the Ten Commandments on Mount Sinai to Moses [1], that provides the benchmark of ethics today. These describe that G-d, Who saved us from Egyptian slavery, did so in order that a people emerge to whom He would entrust the giving of the Torah, the Book of Law, that contains universal laws for all mankind, that represent G-d's infinite wisdom, for all to follow. These Laws, termed the Seven Noachide Laws, as discussed in the Babylonian Talmud are compose of six which relate to Adam, derived from Genesis Chapter 2:16, and one, "not to eat the limb of a live animal", given to Noach after the Flood, were deduced from the Torah by rabbis [2], teachers of Torah's generic intent, as described by Hillel circa BC, which still defines ethics today. Hillel was asked by a would be convert if he could describe the whole Torah while standing on one foot. He replied, "do not unto others what you would not have them do unto you" [3], which relates to both "doing" and "not doing" that which affects another, which applies twenty four hours a day. These are universal laws for all to follow and with the exception of two laws, namely "to set up courts of justice" which ensures society reaches its full potential and "to not eat the limb of a live animal", which ensures individuals reach their full potential, are similar to the Ten Commandments that are specifically for Jews, that also are included in the Generic Torah message, as enunciated by Hillel. Thus the whole Torah was given to provide the ethical benchmark and guide for all mankind.

Ethics is based on a sense of purpose and meaning that for each one of us is the same, directed by something greater than either of us, for the sake of the planet and G-d's wish to be here, in terms of our behaviour and sense of purpose, manifest in how we do things and utilise time, by being both respectful and refined. No-one is hurt by an action or behaviour which is ethical. Thus ethics may begin with self but rests beyond self.

\section{Ethics and Medicine}

The hippocratic oath. Hippocrates (circa late $5^{\text {th }}$ century BC, Wikipedia) wrote a timeless document that beholds us to have the highest regard to what we do, unconditionally in the best interest of our patients. Medical ethics can still learn from this and certainly relate to it. In accordance with this, the highest regard is given to the human body not to show any disrespect to it, whether during life or in death. "Duty to care" acknowledges the patient's wishes by taking these into account, whereas "duty of care" reflects only the perspective of the service provider [5], which is a departure from "respecting rights" [4]-[6]. "Duty of care" raises concerns of agenda and/or questionable ethics as it does not give unconditional support and respect for patient's wishes and therefore respect of patient rights [5] [6].

\section{Context Matters}

Taxonomic classification distinguishes species, genus and in the species Homo Sapiens, also race. Melanin is a 
colouring, a pigment, not a colour. Shades differ. Colours differ and even emit a different wavelength of light or sound depending on how one perceives it. Differences are healthy. Bureaucracy and subjectivity, which are the same, are not. We are composed of similar molecules but respecting rights unites Mankind. Even the same pigment may look a different colour in another light. My point is that context needs to be taken into account. We are at the same time different and the same. What really needs to be evaluated is the concept of a "virgin birth". That must be the ultimate con, a duplicity that ranks over all others, which is why every other duplicity, such as "acting in the public interest", is a duplicity those on Boards and Tribunals can get away with, and those on Colleges who say they are acting in our interests to introduce re-validation, asserting they have our permission to do so, are really making a job for themselves at our expense, and why some groups and individuals are "bullied" and harassed by the bureaucrats, who also "bully" and abuse us [7]. In this [7], too there is no difference, only the context differs. We are all Aborigines in that sense and, called "racism" or not, something has to be done about it.

\section{Persisting with Case Law or Instituting a System of Evaluated Decisions to Determine Right in Context}

A System of Evaluated Decisions [8] is a system of prospective and objective evaluation of the effects of a decision on society, as to whether the outcome, and thus the decision, is good for society or bad, according to an independent committee, independent of those who made the decision and independent of the parties affected by that decision or who brought the action to be decided.

Currently, case law defines precedent and thus decisions, which sets social standards based on sanctioned judicial discretion exercised in the event of doubt. Doubt therefore becomes the basis for self-serving decisionmaking, decisions made where no doubt exists, but is introduced to do so. This permits a judge or Tribunal members who are clearly biased, to decide in favour of the Medical Board, where no doubt exists, as if in fear that were the Medical Board bureaucracy to be found wanting, all would be affected affect fall. Added to this is that hindsight or recall does not guarantee certainty in cases of apparent or perceived bias not only because of the regulator's self-serving agenda and contrivances as to what occurred, but also because it is retrospective. Such bias would not be permitted in a system that is accountable and fair, in which self-serving decision-making and the effects of such bias, in terms of social cost and denying health services and care as well as personal cost, would be prevented. A System of Evaluated Decisions would ensure continuity and provision of health care "beyond the call of duty" as standards look forward to reach new heights as an exemplar of mutual trust and benefit.

Case law is anecdotal. It is retrospective and as it is not tested, and is taken out of context, it is subjective. Appeals may be heard but these are costly and are likely to be subject to a different set of rules, which is like moving the goal posts or changing the size of the playing field. Case law does not provide assurance to those who rely on objective evidence; nor is case law subjected to independent scrutiny, and given that case law was made on cases that differ to some degree from the cases to which that decision may be applied, context that differs demands that relevance be shown that case law applies. In Law, the medical equivalent does not exist as assessment methods that demand objectivity and ongoing review do not apply or are not applied. It would be prehistoric in the practice of medicine to do otherwise.

In order to bring legal practice and judicial decision-making into the $21^{\text {st }}$ century, a System of Evaluated Decisions needs to be instituted to promote a healthy, transparent and accountable society; in order to have an evidence based evaluation tool to determine "what is rightfully" in the public interest; and to replace anecdotal case law, which is subjective and not subjected to prospective evaluation and scrutiny; to set objective standards as the basis of precedent that accountability and objectivity demands; in the interest of the welfare of society; and to provide the parameters of values that guides moral development and an ethical standard of living.

\section{The Issue of Bias in Law and Judicial Process. Learning from Medical Ethical Standards of Accountability. The Medical Scientific Model}

Medical scientific investigation utilises various methods to ensure objectivity including double blind studies, use of controls and random sampling techniques that are subjected to statistical analysis, review and confirmatory testing, which case law does not.

In law "the appearance of bias, let alone bias, is sufficient reason to invalidate a decision" [9]. This principle 
is enunciated in Torah Law, "that a judge cannot accept a bribe” [10], as this blinds him/her to the truth. The problem is that there are no evaluation checks and no independent checks on judicial bias, and bias is redolent particularly when decisions involve Boards or perceived as "self", as Boards are legal bodies themselves.

The relevance of this to medical practice and Medical Board matters brought before tribunals and courts is obvious. Contrived allegations made by the Medical Board are added to patient claims and/or change as investigations unfold. In a declared and transparent process designed to be in the public interest and to protect the public such obsequiousness and duplicity would not and ought to not be tolerated. Yet the Tribunal system thrives on contorting facts, unashamed dishonesty by literal interpretation taken out of context to create doubt, to exercise bias. Doctors on panels are often out of their depth in assessing complex cases and out of date with new advances in knowledge and current practice and those cases outside of their areas of expertise when they were in practice. Experts called by the Medical Board to give evidence tend to subscribe to its dogma or are not given the full brief, only documents or witness statements which support the Medical Board's position. One has to clarify what material has been given. Tribunal members have difficulty accepting wrong can be done by the Medical Board or be seen to be done even when glaring and obvious, which is the reason to demand independent evaluation of decisions by an independent committee/jury and to award compensation in terms of both costs and damages to discourage the wholesale investigation of complaints without discretion by Medical Board investigators and ensuing abuses.

Evaluation of decisions would permit an audit of performance and of decisions of individual judges and tri-bunal members.

There also needs to be transparency and accountability of statements made to different bodies and decisions made at hearings by Medical Boards. These need to be consistent in themselves and with performance to ensure that objectivity not bias determines how decisions are made, what decisions are delivered and which policy the Medical Board holds to.

Just as the public are informed of outbreaks and specific pathogens or viruses are named bureaucracy and institutionalised thinking and those who thrive on this need to be named and their performances open to public view and seen as worthy or not of holding such positions, as all are in effect public officers and servants to do what is both right and good [Deuteronomy 6:18, 12:28], i.e. good in the eyes of G-d [Deuteronomy 6:18, 12:28, 13:19], which is the benchmark of ethical standards. And if worthy to continue, as well as to teach and learn, to practice, but if not then to do community service to cultivate objectivity and desirable connection based on ethics that enhance health, wellbeing and living standards for all.

\section{Medical Ethics and Informed Consent}

Medical ethics is determined by how much better we help our patients cope with the change in their environment by effecting a change in them, whether by increasing their immune mechanisms or resolve or other treatments both preventive and curative and by helping to buffer or make changes in the environment so that they cope better, or both. Informed consent means that decisions taken are done by the patient, unless delegated to the doctor or to a third party, with the best input as to choice and reason for one medical treatment over another given by the medical practitioner as the medical expert, yet decided by the patient's preference.

\section{Pharmacological Companies. Focussing on What Is Important}

Our approach as to whether pharmacological companies can or may or may not give incentives depends on the impact this has or may have on medical practice on a patient-to-patient basis. If the incentives result in enhancement of patient outcomes, then it is good medical practice, but if it introduces bias, then it is not. Instead of blaming pharmaceutical companies, without whom there would have been fewer therapeutic advances, we need to shoulder the burden of responsibility of objective assessment for ourselves, to be educated to be able to objectively assess their products and the effects they have on the treatment outcomes of our patients. We need to be able to assess the trial data and be able to apply them, and we need to be better trained scientifically ourselves. Blame and stopping Pharmaceutical companies from providing advertising or free gifts and samples cannot replace objective assessment and scientific education and training in accountability of medical practitioners for ourselves. Bureaucracy blames pharmaceutical companies, which does not strengthen our own abilities, because this creates a niche, self-servingly for themselves. Colleges ought to be training fellows in scientific method and critical appraisal of study material, instead of promoting abstinence and non-engagement as methods of curtail- 
ing pharmaceutical influence, yet increasing their own bureaucratic controls.

\section{Requirements for Disclosure}

Requirements for disclosure declarations are well founded to ensure the receiver of the information is informed of possible bearing, interest and subjectivity. Similarly, we need to critically view studies, such as head to head trials, which conform to a scientific experimental paradigm, even if double blind does not necessarily guide clinical best practice, unless a best practice clinical approach is incorporated into the study design. The role of sodium intake in studies involved in therapeutics that affect the renin-angiotensin system is a case in point. The fault lies with editors who insist on controlled studies, and reviewers who do not demand clinical relevance. Consequently, though controlled, and conforming to a scientific study design beg the question, "do such studies serve to guide standards of clinical guidance best practice?”. And if not, this raises the question, "can this scenario be considered as ethical?”.

Because context determines ethics, clinical applicability of the trial's design determines whether such a study design is ethical or not. Because "head to head" trials, performed in this way, are not aimed to incorporate best practice in the trial design, editors demand disclosure statements from authors. This would not be necessary if best clinical practice is incorporated into the trial design. However, where trial design is focussed on "controlled" and "head to head" in a non contextual clinical treatment pathway, and use of complementary non-pharmacological methods first or simultaneously is side-lined or not done, disclosure is necessary as the object of the study design is not clinical best practice but pharmacological effect in terms of clinical benefit. Pharmacological effect, not in a clinical best practice scenario, i.e. when taken out of context, requires disclosure as bias may be derived from it.

\section{The Doctor-Patient Relationship. Informed Choice}

The Hippocratic Oath [4] demands that we respect the sanctity of the doctor-patient relationship. At the start of my medical career in second year all students took the Hippocratic Oath to respect the human body. We were about to study anatomy, and to dissect the body. Regard for the body and that a person donated his to her body to science instilled in us the respect all life deserves. Medical ethics in this situation, as in any, demands that we provide the best advice or treatment to control the external milieu, whether this means return home and or to work, as the defined goal according to the wishes of the patient, and in this case, dedicated to educating medical students and to medical science. Similarly, it is the patient's choice based on all the information required to make any choice, information that we have to give them, which constitutes informed choice. The decision remains that of the patient. Advocacy demands that this be respected. The information provided is the science, the expertise that the medical specialist, the doctor, provides. The choice of treatment remains the patient's, as does the goal of therapy, or the patient may delegate choice of treatment to the doctor or to a third party in order to achieve the outcome or goal that represents patient's wishes, i.e. best interest is a personal viewpoint [5] determined by what the patient wishes [5], or would wish if decision-making has been delegated to a third party, whether delegated or not by the patient. It is not ethical to make patient choices for them. The ethical position is to act in the patient's best interest from the patient's perspective [5], to achieve their goal of psychological and social wellbeing [11] [12] — that must be totally in accord with the person's own viewpoint, expressed when they were able or as they currently wish for, being in the best possible state of physical health at the time of decisionmaking or expression of wish. Any departure from what the patient wishes or tokenism does not fall into the definition of "best interest". It may fall into the category of alternative interest or surrogate decision. It is in the author's opinion an abuse to state that best interest is or is served by anything other than that which the person wishes for him/herself. This is particularly relevant to respect for ethics and Rights that must be upheld throughout Guardianship issues and surrogate decision-making, and which needs to be taken into account when reforming the Law [8] [12]-[15].

\section{Do We Learn from Heroic Stands by Irrepressible Patients?}

Recently, an 87 years old man, resident in a nursing home was told he could not attend the D-Day celebrations, 2014. He was 17 years old when he was serving in WWII and the seventieth anniversary of the D-Day celebrations was approaching. You may have heard this story on the news. He was unrelenting, and like a true soldier 
escaped and attended and returned to a heroes welcome. But what does this say about how he was treated? What does it say about what needs to be instilled in health workers? Did we learn from this story? Can this experience also help us to have respect of the wishes of those who are infirm and those who have expressed wishes, or who have expressed their wishes and now can no longer do so?

\section{Do We Value Life Enough to Value the "Last Gasp" of Life? How Do We React to It?}

Life is like a milk shake I told a Palliative Care meeting [13]. The "last gasp" is the last taste of what a wonderful experience life is, not was. Everybody deserves to have it. Even the queen would be expected to make a noise when having the last sip of the shake, through a straw. To use Morphia to prevent this, on the pretext that this demonstrates a person is in pain, reflects a lack of understanding, that 1) there is no pain, 2) the person is not suffering 3) the Morphine is given to satisfy those who are unnervingly affected and 4) who fear the end and or perceptions of pain, which has not been objectively tested i.e. they act on their subjective perception and fear 5) the test of pain can be as simple as speaking to him/her informing the patient of what I am going to do, i.e. change position by rolling, and using the sheets, not cold hands on his/her body, then roll him/her and notice if there is any grimace or expressions or sound that had been previously been interpreted as pain. In the case I did this there was no reaction to what I did, as the motion was painless. Similarly, just because a person is deemed palliative does not mean they need to be given Morphine or anything else for that matter. If that person was able to say so, keeping the milieu extérieur constant would have meant that those who wanted to assert their view over him be removed from there. Their "more fear" did not justify giving "Morphia" to the patient. Education as to technique and to rights at the end of life, to live life with gratitude, understanding and appreciation, is needed.

\section{The Definition of Abuse}

Abuse in my view, is the result of an action or inaction against the expressed wishes, now or in the past, of another and/or to which to which they object [14]-[16].

\section{Elder Abuse}

Elder abuse is an action or inaction taken against the expressed wishes, whether stated now or in the past, of an elder and/or to which they object or would object.

Elder abuse may take several forms: social (isolation), financial, physical, emotional or psychological, sexual, denial of natural justice. Elder abuse applies to anyone. It is not limited to someone in whom the elder has trust, e.g. a family member, but is relevant to anyone as trust in others is a foundation of society. We are therefore en-titled to have trust in everybody especially government workers or public advocates and public guardians, whom parliament has entrusted to serve the public good, yet who would rather be excluded from the definition [13], which is in itself indicative of denial of natural justice as this would set them above the laws prohibiting Elder Abuse. Ethics has to apply to all, to ensure that "best interest" is relevant to all.

\section{The Constancy of the External Milieu and General Systems Theory (GST)}

General Systems Theory is based on the principle that the world is created in physicality to function in pairs. Thus action or change in the environment results in an organism's response. Response may be by escape or adaptation [17] as far as the internal workings of the organism is concerned to maintain a constant plasma and lymph i.e. extracellular fluid environment, optimal for cellular functioning to continue. Just as the constancy of the external cellular environment has to occur for ongoing life and function, as explained [18], the individual also responds to environmental change, either by escape or to control the environment, to either reverse or limit the change or to transform it i.e. to maintain the constancy of the milieu extérieur for ongoing life, function, pleasure and enjoyment.

Two biochemical principles operate to permits this: 1) innermost membranes maintain (the composition) of fluids external to the membrane within and optimal range. This occurs at all levels of biological organisation. 2) The persistent disturbance of the external fluid at any level of biological organisation will result in a change in the inner fluids [18]. 


\section{Eco-Social@Relevance}

Eco-social ${ }^{\circledR}$ Relevance [19]. The more diverse the environment the greater is the wellbeing of the creatures, including man, living with it. Adaptation may be adequate and appropriate leading to evolution if breeding and survival is enhanced; to disease if adaptation is either inadequate or inappropriate; to aging (loss of functional reserve capacity) if change in the environment is not sensed i.e. not responded to $\left(\mathrm{O}_{2}\right.$ and Reactive Oxygen Species); and to death if the environmental change is sudden or overwhelming. Likewise, behavioural response is an attempt to control the external environment. The extent to which the individual is able to harmonise with the natural environment and maintain it to be able to live well within it determines wellness in an Eco-social context and environment.

\section{Ethical Response}

Ethical response is behaviour that reflects appropriate and/or adequate inner change and adequate or appropriate response to environmental changes/challenges, which benefits all and which enhances diversity i.e. is behaviour that has contextual relevance. Contextual response demands consideration of others, which benefits all, i.e. enhances diversity [19] [20].

\section{Unethical Behaviour}

Unethical behaviour is response irrespective of and or in denial of or indifferent to and/or in spite of context [7] [20]. Unethical behaviour is characterised by any or all of the following:

- It is maladaptive as it impacts negatively on the environment - to the individual's perceived advantage.

- Rationalisation of behaviour, or denial or indifference to harmful effect(s).

- Which is not provoked by the situation one finds oneself in now, i.e. has no contextual relevance.

- Is related to previous environmental reaction or "baggage", whether real or not.

- And where blame is denied or fabricated, or even acknowledged, but which does not accept personal fault or reason why behaving as such.

Sincerity, honesty and integrity. Is there a difference, does each stand alone?

Sincerity implies commitment but does not differentiate between commitment to do good or to do bad. Therefore honesty is needed to be able to reflect on doing "Good", which means doing acts of goodness and kindness, or of being just and kind. Integrity is the arbiter of this as integrity recognises the relevance of context. Therefore honesty and integrity determine ethics. Sincerity indicates level of commitment.

\section{Context and Medical Ethics}

Medical Ethics, no different to Ethics, demands an understanding of context. For example, a person seen cutting their finger with a knife may be removing a splinter, or be a surgeon performing the necessary operation using a scalpel. This does not constitute unethical conduct, whereas the same action done without informed consent is a matter of professional conduct and could be considered as a criminal act whether or not in a medical context.

Is medical ethics subject to fads and to change? Just as ethics and morality do not change, medical ethics is not subject to change. However, behaviour patterns and tolerance of abhorrent and unnatural behaviours which are self-serving and agenda driven to ensure that one or other behaviour, be it regarding sexual relationships or terror, which are agenda driven. These represent an attack on the fundamentals of society. The basis of a functioning and fair society for all, in the context of human achievement and fulfilment in life and sense of Oneness of purpose, is that happiness is the goal of life by living according to standards that ensure happiness now and for all. The ethical fabric of society is its template. This requires objectivity, and the promulgation of caring and responsibility, values that are both old and true, and which are everlasting. Behaviours may change, but ethical standards have withstood the test of behaviour challenge and time and proved time and again, that they buttress society and achievement and success and wellbeing for all and are not subject to change.

It is necessary now to include habitat protection of insect (e.g. earth worms, bees), animal and plant life in sea, fresh water and on land in healthcare, as their wellbeing and diversity affects food chain and hydroponic cycles which affect us all. 


\section{Health Law}

The Health Professions Registration Act 2009, as does/did its predecessor the Medical Practitioners Act 1994, defines unprofessional conduct as "according to what one's peers and or the public thinks". There is no census done, nor is there insistence that the patient's view has to be respected or taken into account, which opens up a myriad of vexatious claims or opportunity for any third party to do so if they wish to or have a vested interest, and without the patient's knowledge or consent or even against the patient's known wishes make claims against the patient's trusted and caring doctor.

Bias, in cases involving the Medical Board, goes by without an appeal, not only as legal battles are costly, because one is not only fighting for justice but against an injustice in the form of the courts and Tribunals them-selves.

In Australia, bureaucracy and judges as members of tribunals and courts, even the High Court and in the Su-preme Court, the Chief Justice, ignored the relevant Law (see below) and bipartisanship, that, had they taken it into account, would have ensured that the Medical Board could not have been awarded a win and costs and more importantly, would not have lost the opportunity to have set a precedent to ensure Elder's rights, which others were later, in part to ensure, in certain circumstances (see Australian Health Care Standards update, below). Instead, their decisions abetted Elder "abuse" apparent in the writing of allegations-such as "you acted as the patient's advocate...”, denied natural justice, and ignored the rightful Act, the Medical Treatment Act 1988, which was enacted to bolster the rights of a patient to refuse treatment and for the doctor who respects the patient's rights to be exonerated from civil, criminal and Board proceedings. This Act, in its preamble, also recognises the difficult circumstances surrounding end of life issues in which doctors find themselves, as occurred, that required advocacy on the patient's behalf according to her wishes e.g. having to advocate for the patient, at her request, and that of her husband, also Dr Myers' patient, in the face of third party showings of self interest, anger and threats to prevent the patient from going home as was her wish, and to which the doctor whom she trusted responded, at her request, and in her and her husband's best interest [21]. Yet this commendable advocacy on behalf of his patient's, described as "beyond the call of duty" by his peers, was found wanting by the Medical Board, Tribunal and Chief Justice and not fitting of special leave to apply in the High Court, indicates the "unspoken loyalties and bias" that attends such injustice and shows even more the integrity of judges who thought otherwise [21], who in granting leave to appeal the Supreme Court decision said, "There is error in respect of the decision below, wrong were the decision to stand and tenable argument open to the applicant-we therefore grant leave to appeal (the Medical Board decision, Victorian Civil \& Administrative Tribunal decision and the Master of the Supreme Court decision as well as the Supreme Court decision)".

Since 2013 the Australian Health Care Standards (AHCS) [22] [23] has recognised the need to address this. Based on "Patient Choices" started by Michael Silvester, Associate Professor at the Austin Hospital, Heidelberg, Vic. in 2001 AHCS now support the patient's stand that ensures that patient's wishes are upheld, and in similar circumstances, albeit in the intensive care unit [22] to the situation above. Thus the High Court's refusal of Spe-cial leave (Hayne J and Crennan J) to appeal Chief Justice Warren's decision, and that of Chernov J and Bell J, became superseded in time by health standards that in 2000 Myers was prepared to uphold, before any such similar stand was public policy, by advocating for his patient's wish, which defines personal best interest, to return home, as was her husband's request that she do so once treatment was completed, as occurred, as the patient was deemed palliative. The social worker's interference and fear of the patient's daughter in law, who wished to prevent the patient's return home, led to a Tribunal hearing in which, to the social worker's surprise, it was ordered that the patient return home, as was her wish. A complaint to the Medical Board by the daughter in law, unbeknown to the patients, led to the Medical Board's wrongful support for the daughter in law's stand that the patient not return home, and abetment of Elder abuse on their part as denial of rights was also against the Law. The Medical Board's decision was not only shown to be wrong with the passage of time vis a vis the AHCS adoption of "patient choices", their actions were in violation of the United Nations position as at 1991 and the Medical Treatment Act 1988 (vic.gov.au).

Tribunal bias towards the Medical Board of Australia also manifest as dismissal. Applications against the Medical Board of Australia and against the Australian Health Professions Registration Authority (AHPRA) for contempt of the Law and alleged misfeasance are dismissed [24] and are even described as vexatious in order to provide a basis to award costs in favour of the Medical Board, despite their contempt of the Law and alleged misfeasance or to cover it up by taking the path of least resistance, though unjust and a denial of rights and 
natural justice.

The Victorian Government Legislative Council Inquiry into AHPRA, March 2014 is an essential read for all interested to expose AHPRA's and the Medical Board of Australia's failure to ensure health services and to protect the public, which are meant to be its aims but which it uses instead, as a camouflage and guise, to mis-lead the public and the health professions to believe that its misuse of notifier allegations and health professions abuses are in the public interest, ensure health services and guide doctors.

\section{The Ethics of "Not to Treat"}

The dying patient. The goal of life and the goal of medical treatment is to ensure patient happiness [4]. Happiness is a state in life. There is no happiness in death. Euthanasia is not the key to happiness. Euthanasia is not compatible with life nor with a compassionate approach to life. Euthanasia leaves one speechless. The answer to terminal illness is empathy and compassion. The answer to severe pain is pain relief. The answer and indeed effect of both is to ensure comfort. If the means to achieve comfort result in death, then the decision to provide this must be made with all those close to the patient, to keep them in the know and in the decision-making process. The patient's condition does not need to be prolonged, but the more people who can see, feel and hug and or speak to the patient before death the more calm they can be afterwards and wholehearted that they have achieved by adding to the patient's comfort, not only now but for the onward journey beyond, yet connected to this life by adding appreciation and meaning to it.

\section{Capacity vs Cognitive Assessment. Quality and Safety vs Rights and Responsibility}

Neuro-psychological reports gauge cognition. They do not evaluate capacity [5]. Cognition or deficit that may be present cannot be said to override capacity, defined as consistent belief or wish; awareness of what one does not wish for and satisfaction when wishes are respected and fulfilled, is present when the patient is consistent in the expression of their wishes, failure in the provision of which has adverse consequences such as lack of motivation, lack of will, withdrawal and depression, but one does not have to see these or test the situation to be convinced. Accepting the person's word as to what is their wish is sufficient. Some people add, "and knowing the consequences of their wish" although this is more in relation to Wills. However, predicting consequence is often used as a lever by non-clinical decision makers, bureaucrats and service providers, or by para-health professionals including nurses, social workers and occupational therapists, even neuropsychologists, or third party doctors or doctors not trusted by the patient or appointed by the patient. Unless appointed these parties have no right to override the person's wishes, or invoke "duty of care” and safety issues, as opposed to “duty to care”, to control the choices and movements of the person, as to goal, such as return to work and choice of residence.

The argument for "quality and safety" is a conundrum [25]. Quality means free choice and acceptable risk whereas "safety" overrides this, showing a double standard. Safety and quality applies to services and products such as toys and cars. Rights and responsibility applies to people [26]. Support for the patient's wish ensures psychosocial need that determines emotional state. Happiness is the goal of patient treatment. The factor which most determines "goal achieved" is patient motivation, and "Goal achieved” or "wishes respected” ensures patient happiness. This is not a utilitarian view. It is a "values based” view. It is primarily about respect for another and that wishes be respected and ensured, clearly, within the Law (Medical Treatment Act, 1988), which is universally accepted [11], as long it is not to detrimental of rights of another, i.e. has contextual relevance, and therefore is ethical.

\section{Whether to Treat Or Not to Treat to Save Your Own Backside?}

Boards and Tribunals say "the doctor puts himself/herself in danger by treating an infatuated patient or one who complains”. The answer is if the doctor has not abused his/her position of trust and has only advised the patient in the best way, however unconventional, no ethical compromise exists, if, on objective grounds no harm was done to the patient and no harm was meant. Patients have to be ethical as well, respecting the mutual trust on which the patient as well as the doctor enters into the relationship. Balking by one or the other compromises trust as well as the ability to treat and be informed in order to make the best choice of treatment. 


\section{Global Application of Psychiatric Awareness}

Understanding the psychiatric scenario helps to understand antisocial behaviour, not only of individuals, but of individuals in groups, communities as a whole, and even sociopathic national identity that is aimed to appeal to other peoples' sense of compassion above reasons, to support a cause that has "evil" written all over it, as the consequences are grave were their cause to win, as their aim is genocide, rather than reflection and correction and working to achieve and regain respect of self and purpose, which is to help others rather than manipulate them to serve self and manipulative/cunning/their devilish purpose. The ethical response is to see through this and effect behaviour changes to debunk their view and transform it or treat it to become an ethical point of view. Because war results in casualties and deaths this is also the province of the understanding medical specialist and specialist medical ethicist, who understands the meaning of context.

\section{Medical Boards and Context}

Not taking context into account provides a contrived reason not to apply a common sense approach to under-standing complaints. The Queensland government in Australia appointed an Ombudsman to field complaints in place of the Medical Board, because of the latter's standard of performance. The Legislative Council Inquiry, March 2104 (the Inquiry, 2014), Victoria Government, found the Medical Board delayed proceedings and undermined the national health agenda. The Medical Board's failure to provide 2012-2013 financial in their annual report and their own internal funding arrangements that rewards complexity and duration of investigation as the basis for their internal funding arrangements is concerning and concerned the Legislative Inquiry, as delays and making cases to be more complex, rather than simplifying and efficiently resolving disputes or issues is the apparent basis of their internal arrangements/allocation of funding. The Health Ombudsman reported to the Inquiry 2014, that Medical Board's generated delays hindered effective dispute resolution and created a more complex situation with less opportunity to be able to reach a resolution.

Clearly, governments need to act and doctors and all health professional need to protest in being threatened by an abusive and bullying, self-serving Medical Board. Colleges ought to stand up to this on behalf of the profession and our patients and as an essential regard for advocacy of patient wellbeing. That the college of Physicians does not is because of its weakness, subservience to the Medical Board, concern about being usurped by the Medical Board's threats to be a credentialing body, which the Law supports and therefore must be changed, as it is failing and has failed as a disciplinary body, as the Queensland government found, appointing an Ombudsman from July 01, 2104 to deal with complaints instead, and as the Inquiry 2014, has shown, while retaining the function of the Australian Health Professions Registration Authority, AHPRA, per AHPRA Act 2009, as a registration body.

\section{Wellness Can Be Assured. The Ethics of a Preventive, Proactive Approach}

Wellness is assured by doing what is both right and good, or kind and just, now, i.e. by utilising the present moment to do what is both just and kind. Wellbeing and wellness are the same and denote psychological and social wellbeing as opportune [12] and appropriate [19]-[23], as context is taken into account.

On the other hand, words such as "should" imply guilt, regret, uncertainty about the future as well as undermining confidence in relation to the present by referring to the past in ways that do not address the complaint or alleged reason for it. Being focussed or making conditions premised on the past and or future prevents one from acting to relieve the problems.

It is only by acting to do "Good noW!" ${ }^{\circledR}$, which includes the strengthening of motivation and resolve and helping another or being an example which encourages others to do the same, i.e. by noting that any act (or not acting), is an achievement. Every achievement that one does, every moment being the opportunity to do so, noW!, builds confidence on which to rely. This in turn feeds confidence and action based on knowledge, reflection, advocacy and honest and independent evaluation, which are the basis of ethics in medicine and wellness both in and outside of strict medical practice, but with which we, as primary health professionals and acknowledged leaders in the field, need to also to be actively concerned. There is no restriction to doing so. Everything from use of language, to what to do and what to not do, to building character and positive attitude are included. It is in this author's view, unethical to not do so. 


\section{Accountability and Ethics}

A values based society is one that acts with transparency and accountability; with time for reflection; with encouragement and support for such motivation and motivation to positive and constructive action in consideration of the rights of others. Accountability determines ethics in medicine as well as law. It also is inherent in clinical medical practice and application of scientific discovery and design and review of research findings.

\section{Understanding the Psychiatric Patient}

Complaints by psychiatric patients need to be assessed from the perspective of psychiatric illness. What is psychiatric illness? What makes it happen? Is it treatment aimed at maintaining it or actually to overcome it?

In terms of General Systems Theory, i.e. the concept of the constancy of the milieu extérieur [18], the organism's survival is dependent on escape or adaptation [17]. Adaptation includes the organism's ability to change internally or to reduce and or reverse the environmental change or to minimise it [18] [19]. In these terms psychiatric illness is a manifestation of egocentricity that arises because of a feeling of having been misunderstood [20]. Everything then adds to this until the person withdraws, reacts out or develops coping mechanisms based on blame, others need to change to satisfy me, manipulation and strategies used to test the strength of relationships to breaking point, upon which they say, "you see I knew it, you do not love me or care about me”. True the other can never please appease nor win. Thus treatment has to take another line, a coping strategy to overcome the devilish selfishness that drives sociopathic behaviour and manipulative behaviour. We have to challenge the person to develop a sense of humour, by playing the tape back at them, and not by succumbing to their demands. We have to move from the rational response to the unexpected that would seem unorthodox and not in keeping with tradition or rational, yet it is. It does utilise the element of the unexpected" that is at least one step ahead of the predicted response by undercutting it, by introducing a sense of humour. Thus there is an "ethical shift" from routine and rational treatment of physical complaints to "irrational and unpredictable responses" to psychiatric drives and psychiatric illness, that are themselves "irrational and awkward". For instance, the patient stated, "doctor I am confused and cannot find myself”. The doctor replies, "You'll find yourself in your slippers". And the next morning when the doctor visited his patient early, she said, "doctor I have found myself in my slippers". She recovered. A good sign of recovery and of compliance was when she went on to use the AHA "Good noW!" ${ }^{\circledR}$ strategy to continue to improve through self empowerment, saying, "I am doing it my way", "AHA".

AHA stands for Australian Heath Ambassador, but it could also be Asian, American, African, Alaskan, Arctic, Antarctic, Europe and Asian and Middle Eastern AHA "Good noW!" AHA means..., wake up!, to do "Good noW!", speak "Good noW!” ${ }^{\circledR}$ and think "Good noW!"”, ambassador. Motivation and sustaining motivation is the key, which this does by becoming evident that it is fulfilling and that as much fun and environmental control can be effected by reaching within to reach without, as by being self focussed and egocentric, but with positive gain and return to independence, and empowered to relinquish psychiatric manipulation and maladaptation to the past, and move forward able to adjust to life's challenges as opportunities to strengthen bonds people one cares about built on trust generated by gaining confidence, self respect and focus on wellness which is directed not only on self but others which builds an external milieu of ambience and opportunity, based on love and honesty, doing acts of kindness and mutual trust.

\section{The Bureaucrat's Conundrum}

A forward looking approach ensures provision of health care "beyond the call of duty" as standards look forward to reach new heights as an exemplar. Looking backwards or to the lowest common denominator as the point of reference in health care as bureaucrats do under the guise of doing good, is to impose their negative non-creative attitude, that is the basis of the bureaucrat's inherent psychopathy, of inferiority and unrequited despair, onto others, on society, on whomever they can or whom they perceive as achievers, to "have to pay" or be punished for. Administrators, by contrast, are actually people who encourage, support and care. They do not bring personal "baggage" to work with them i.e. they are driven by a work ethic in the public interest.

The bureaucrat does the opposite as they are driven by a self-serving agenda that characterises psychiatric or maladaptive, unethical, behaviour - the "psychiatric personality", who presents in the form and guise of the bureaucrat, whose pretence is in name only, in the interests of the public good, in terms of "to protect the public", while being wholly and even in part, self serving.

The solution to this, for bureaucrats and those subjected to them, is to regard every occasion as an opportunity 
focussed on the present moment, to do "Good noW!"®.

\section{Stigma Is an Ethical Health Issue and It Requires a Healthy Approach to Deal with It}

Why is stigma attached to being diagnosed as "psychiatric"? Is it because psychiatric disease connotes "madness". Or, is it also because the "psychiatric patient, once labelled, is not treated for cure, but for symptom control or behavioural management? In this we have to ask. "Has little advanced in seeing a cure for psychiatric illness the result of "treating the patient in order to make a living or providing the patient with life empowerment and life empowerment strategies?". Would the prescription of a picnic a day or "the four wheel drive treatment" a day, a ride in the dunes with your husband or wife, be more effective than a tablet a day?

This relates back to conduct and response to environment. A psychiatric patient is one who either does not wish to change their own behaviour but wishes to control everyone and everything else around them, the ma-nipulative patient, or withdraws because it perceives the environment as threatening not because it necessarily is, but because of being too or oversensitive. This, in my view, reflects the withdrawn and the schizophrenic patient. The depressed patient is one who sees the whole world from their subjective viewpoint, as a burden or arising form misunderstanding or perceived misunderstanding as wanting more love, by manipulating their response as if it is never fulfilled, never understood, never enough consideration, because they are self centred, undeserving in their own estimation of the care given as they can never have enough, nihilistic and described as "human black holes. It is unethical to pander to manipulating patients, in my view. They need to be told, do something for yourself, to adapt, with or without incentives, and definitely not with incentives that disadvantage others or put others to a further test. Discipline is necessary to control ones feelings and emotions, desires and wants, the path of least resistance. Similarly, the egocentric manipulator and the depressed patient need to be encouraged to develop other interests, to do a kindness for another, which is a big ask, so start with doing something that is guised as in the interests of the agenda related to self. Education is required, as well as understanding that they have support for being the victim only if they improve their game. The problem is, these people are not prone to change. Though help is given they seek to find others or another always to blame. Ethics demands that this knowledge is known, so that health professionals do not suffer when complaints are made and to educate health professionals to not take what these people say at face value. They are manipulators, which indicates that what they say has undertones and intents. Their words change. What they say cannot be trusted at all. Nevertheless, as therapists we are not here to create stigma but to relieve people of it, especially those whose manipulative tactics are dependent on it. Occasionally, as shown above, behaviour therapy and positive and applicable suggestion given as advice, works in the form of do "Good noW!"

\section{Ethics and Bureaucracy Do Not Co-Exist}

Bureaucracy is probably the greatest plague that faces us. Unlike honest administration, which is designed to help and offer assistance to us to create a more supportive environment, bureaucracy seeks to become the environment and to dominate those whom they wish to trap within the limits of time and space that they regulate. Legislation provides them the power to make us prisoners of metered space and measured time. Doing so permits bureaucracy to challenge creativity and entrepreneurship and risk taking as part of life. Bureaucracy is about self-serving empowerment and regulation. The limit lies in accountability, in a System of Evaluated decisions and award of compensation part of which bureaucrats themselves have to pay for. Just as professional indemnity covers doctors for "malpractice" and ought also protect against opportunistic claims, insurance for bureaucrats would be a step forward, at least to indicate self awareness of accountability and that "i could be wrong, or have a made a mistake" instead of showing fear of admission of wrong; deception to cover up wrong and collusion between agencies of government, such as the Medical Board (and other Boards) and Tribunals, as well as courts, with notable exceptions as individual judges do impartially decide (see decision, Buchanan J and Nettle J. [VSCA of 2004]) [21].

\section{Discussing Sexual Issues with Patients}

If one is of the view that mutual trust is the basis of any relationship, doctor-patient or any other, then this allows frank discussion to take place, if this is the patient's need and discussion is by consent or in answer to a question 
initiated by the patient. It is when self interest intervenes that the question of taking advantage becomes real. If the discussion or even action such as examination, is only with good intention, to which the patient has given consent, and is not for gain, there can be no question of abuse and thus of an unethical gain. Patient's may ask a question that catches the doctor somewhat off guard. It would be prudent before providing a response, to interject with the phrase, "do you give me your consent to be frank with you?, as I am in all other situations, and to cover myself. If so I shall provide my response.” It would also be prudent to have the patient repeat the question and to tape it plus the answer you as the medical practitioner provide. Thus everything is recorded in context, in case any questions or complaints by the patient arise, especially if asked by the patient who admits to being manipulative.

\section{In Vitro Fertilisation and Single Sex Parenting and Limits of Fostering}

Advances have been made to ensure infertile couples can bear fruit. Ethics demands that children have rights. As they are minors it is their interest as well that society is in trust of. Children are not owned. Having children is a privilege not a right. Therefore children's rights prevail over ownership rights. According to the Biblical account, which is to ensure moral teaching, we were created by G-d and told to be fruitful and multiply. Fruitful begins with pollination. Pollen is located on the anthers, which is the male part of the plant, which needs to come into contact with the stamen, which is the receptive sticky part of the "gynaecium", or female part, of the plant, which is the pollination process. This requires a male and female contribution. Human fertilisation is no different. Thus to be fruitful and multiply excludes single parenting, however fertilisation occurs, which ensures rights are respected and the issue of ownership i.e. single person or homosexual couples and provision of in vitro fertilisation for the sake of the "owner" and ownership of a child does not occur.

After birth accidents happen and every child born is not always fortunate enough to have a father and a mother who are the biological parents to nurture them. Even so, the idea must still be there. Thus it says in Psalms, “Though my mother and father have forsaken me, G-d has taken me in” [27]. Grandparents sometimes substitute for the parents. In Torah law these can be regarded as the same. Foster parents need to have respect to this and ensure the child's rights to both parents for their upbringing can continue even in their absence. Stolen and lost generations occur when fostering attempts to replace this.

\section{Survival of the Fittest-From the Ethical Perspective}

Every fulfilling aspect of life is ethical.

Ethics wins when there is a sense of purpose that recognises the value of diversity and that the fittest and survival is not devastation but rather the wellbeing in the diversity around us, our Eco-social ${ }^{\odot}$ environment [19].

Medical ethics means to care about environment, to care about the environment of our patients, their Eco-social $^{\odot}$ environment. We need, also, to be more vocal in terms of saving the world in all its diversity and to recognise that egocentricity in the name of bureaucracy, causes, psychiatric manipulation or any other cover up, even religion which is a cover up for power, is the scourge, which threatens survival on this planet. Those who poach animals or what belongs to another or who wish to disturb the eco-social fabric of society and what it relies upon, namely a diversity of healthy fauna and flora, are doing an injustice. The yellow card, red card system is indicated as well as education, until they can be reintegrated into society, of their own, that they are forced to run, and be involved in.

Responsibility given is responsibility shared in a system, which is based on accountability and evaluated decisions as the foundation of judicial decision-making.

\section{Indigenous People, Natural Environment and Medical Ethics}

We need to ensure indigenous people can continue to be indigenous without harm or threat; that the natural wild is regarded as our bonus to protect and be educated that it is that same wild that protects us as well as everything in it, so that, as one tireless worker in Africa trying to save the wildlife and lions there said, "not to become a farming planet", which would not only be a major disappointment, but "the beginning of the end" for all of us instead. Africa, I told attendees at the first Eco-health meeting in Melbourne in 2011 is better as a game reserve than an abattoir. Ethics in terms of context means having regard to our surroundings, and the realisation that the creation of Mankind is not for Mankind itself. It is inclusive, to care for and protect the environment, and all the 
diversity in it, including one another, though we can be poles apart, it is the recognition of this that binds us [28].

\section{The Solution Is Awareness and Accountability in Practice}

Medical Ethics demands understanding the effect, even of our eating patterns, as well as behaviours on the developing foetus [18]; that we concentrate on teaching parenting skills in schools; address the future by empowering our children to make responsible decisions and ensuring that judicial decision-making is not based on subjectivity and on discretion driven by doubt whether real or not, that is unchecked and that leads to society being in a state of disarray.

As medical doctors, wellbeing is "ours to enhance, maintain and protect". We need to have a greater say, as do our youth in what happens now, whether in how we live, where we live, the cities we live in and the rules by which we relate to the environment and to those we not only see, but have not yet met. Focussing on function rather than classification and disease, and on what is happening now, and what are we each doing at this point in time, noW, to do “Good noW!" ${ }^{\circledR}$, determines what happens next. Similarly not doing “Good noW!" also determines what happens next. The question of ethics is to do good now as this determines what happens next is likely to be done in a more favourable environment for whomever is affected by what doing good now represents i.e. having regard for another, doing a kindness for another, which is the best kindness one can do for oneself, a comment made with tribute to Rabbi Lord Jonathan Sacks. The whole focus of the Lubavitcher Rebbe's message as contained in Torah, is to do an act of goodness and kindness, as stated in the name of Rabbi Moshe ben Maimon, Maimonides (1135-1204), "one good deed will not only change you. One good deed effects good in the world and a preponderance of good deeds by adding one good deed to the equipoised scale of good and "bad", which is the way to view the world (and your contribution of one good deed)."

\section{The Concept of Free Choice, Free Speech and Diversity, Fittest and Survival}

Free choice does not mean free to choose whatever one wants to do, just as free speech does not mean free to say whatever one wants or wishes to say. Free implies ethics. Thus free choice and free speech mean free of bias, free of subjectivity and free of doing anyone, plant or thing harm. Free choice means it must allow free choice for all. Free speech means it must permit free speech for all. If harm can or does come from either it is neither free choice nor free speech at all. Context says it all [19] [20] [27] [28]. But there is also another aspect that of ensuring wellbeing in the context of diversity, so that the real meaning of survival of the fittest is not to be the last person, thing or whatever standing. Rather, survival of the fittest means a diverse and healthy environment for all [20] [27]-[29].

\section{What If the Law Supports What Is against One's Conscience}

There are several circumstances that come to mind. Whether to do in vitro fertilisation for other than a heterosexual married couple is something an in-vitro fertilisation clinic doctor will face where it is legal to do so. But many instances of request for abortion may confront a doctor. Whether or not it is legal to do so does depend on the age of the foetus or risk to the health of the mother at any stage during pregnancy. But what if, as occurred, a married couple want to have the pregnancy aborted because of the sex of the child who is healthy and the mother is healthy, and the father is insistent? The doctor involved exercised his right to say "No". Did the doctor have to provide a referral to another practitioner or not, who would do so? I think not, but perhaps add, "You may attend the public hospital". It is better to stand up for what one believes in and risk deregistration than commit to outlandish and obsessive morays that are unconscionable. Where the adult is capable, one would think, of making decisions but has a belief that is against the medical viewpoint, e.g. if a Seventh Day Adventist objects to being given blood, ask the patient or the patient's Enduring Power of Attorney, Medical, to sign to eliminate conscience due to risk, and in the case of a minor call on the Office of the Public Advocate to act as a Guardian would if there are no other appointed adults involved. Similarly, the problem may surface that someone has signed an Advance Directive. This is akin to an expression of belief, as the future cannot be known, but is produced and was not witnessed by a doctor at the time. What legal authority does it hold? If the Directive states, "no" to treatment, is one bound to not treat in the instance where the Advance Directive could not have foreseen the exact situation, and only fluid replacement of blood transfusion is required? I believe Advance Directives not witnessed by a doctor are not binding as the person may not have been wholly informed, and there- 
fore, as the doctor-patient relationship is a mutual agreement, the document is not medically binding. I believe the appointment of a trusted person to act as Enduring Power of Attorney, Medical, is in a better position to assess the situation, because even with the best intention the future cannot be foreseen. This is true, no matter how close to the time and less so further from the time that the action/decision may or may not need to be taken. However, in the event that Advance Directive is made, a doctor needs to be a signatory so that there is evidence that the person had capacity to make the advance directive and in the hope that the situation that could arise was fully explained. To show this I have suggested the document devised be called "Advanced" Directive rather than "Advance Directive", the "d" after advance indicating a doctor was signatory to the directive expressing the wishes of the person [30]. These documents cannot be used as surrogate documents to be able to perform euthanasia or stop treatment of a transient nature where the intention would have been to stop treatment of a condition or not treat on the basis that the condition is treatment resistant.

\section{Jokes, Ethics and a Sense of Honour}

A joke is something intended to make one laugh. It does not matter whom, and it does not matter about whom. But are jokes ethical? Jokes about others, laughing at another, is unethical, as it belittles another. Such (jokes) arise from misunderstanding. They are symptoms and indicators of ignorance and lack of understanding. A sense of humour, on the other hand, is a manifestation of the realisation of self in the context one finds oneself in. Where there is recognition of context, ethics prevails. In other words, a sense of humour is the realisation that, "this is happening to me" and being able to reflect on the significance of "why is this happening to me?", and seeing the funny side of it-being able to laugh at the predicament, and in that state of reflection and humility, become aware that that is the whole purpose. Humbling experience brings out the best in us, the best sign of which is having a sense of humour in that situation, as an expression both of gratitude and joy, an expression of privilege of life. It is a point of wisdom and understanding. The laugh is simply a release. It is an expression of wonder unable to be expressed in words. It is the highest ethical achievement as with it comes a greater understanding of the predicament of others i.e. of others' issues and or joys, in relevant context of one's own sense of purpose realised through the humility of seeing that one is a star in the night's sky, important, as one of them and also unique, yet wondrous being amid the beauty not only in each but in the collective wonder that recognises an all inclusive universe beyond self, inclusive of self and others.

\section{Conclusion}

Not only must ethics dictate what happens in the medical context, but also medical ethics must have regard to context. In that respect medical ethics is in a position to transform unethical but legal decision-making and judicial process in order to ensure society as functioning, in the interests and wellbeing of all, for all.

\section{References}

[1] Deuteronomy 5:6-18 (2009) The Ten Commandments. In: Scherman, N. and Zlotowitz, M., Eds., The Chumash, The Stone Edition, ArtScroll Series ${ }^{\circledR}$, Mesorah Publications, New York, 969-971.

[2] Noahide Laws (2014) http://creationwiki.org/Noahide_law

[3] Hillel. In: The Babylonian Talmud, Tractate Shabbat, 31a.

[4] Myers, J.B. (2007) "Duty to Care”, Or, "Duty of Care” and the Goal of Medical Treatment. Internal Medicine Journal, 37, 211. http://dx.doi.org/10.1111/j.1445-5994.2006.01306.x

[5] Myers, J.B. (2006) Ethics and Professional Medical Opinion and Guardianship and Administration Legislation. Internal Medicine Journal, 36, 540-541. http://dx.doi.org/10.1111/j.1445-5994.2006.01111.x

[6] Myers, J.B. (2010) Clinical Indicators: The Role of Patient in Goal Setting, Evaluation and Ethical Practice. Internal Medicine Journal, 40, 244-246. http://dx.doi.org/10.1111/j.1445-5994.2009.02151.x

[7] Myers, J.B. (2009) The Australian Medical Draft Code of Professional Conduct: Good Practice Or Creeping Authoritarianism? Medical Journal of Australia, 191, 190-191.

[8] Myers, J.B. (2012) A System of Evaluated Decisions. Capacity Assessment: Who Can Decide? Australasian Journal on Ageing, 31, 67-83.

[9] (2013) Ensuring Unbiased Democratic Decision-Making: Principles to Guide Good Practice. Department of Planning and Community Development. Victorian Government. J2,7; L5, 9; M2-3, 9-10. 
http://www.dpcd.vic.gov.au/_data/assets/pdf_file/0005/134483/2013-Ensuring-Unbiased-Democratic-Council-Decisi on-Making-April-2013.pdf

[10] Deuteronomy 16:19 (2009) Ibid, 1025.

[11] United Nations General Assembly (1991) Declaration of the Rights of the Elderly, approved by the United Nations General Assembly on 16 December: Independence, Participation, Care, Self-fulfillment, Dignity. Resolution No. $46 / 91$.

[12] The Law Reform Commission (2010) Guardianship, 17.49, 384.

http://www.lawreform.vic.gov.au/sites/default/files/Guardianship_FinalReport_Full\%20text.pdf

[13] Myers, J.B. (2005) Submission: Elder Abuse Prevention. Office of Senior Victorians. 6 October 2005.

[14] Myers, J.B. (2007) Submission to: House of Representatives Standing Committee on Legal and Constitutional Affairs Inquiry into Older people and the Law. LACA Reps. Parliament of the Commonwealth of Australia.

[15] Myers, J.B. (2010) Protecting the Rights of the Aged and Individuals Referred for Health Care. ANZSPM (Australian and New Zealand Society of Palliative Medicine) Conference, Adelaide, 14-17 September 2010.

[16] Myers, J.B. (2010) Ars Moriendi-Ars Vivendi-The Art of Living Life to the Full. ANZSPM (Australian and New Zealand Society of Palliative Medicine) Conference, Adelaide, 14-17 September 2010.

[17] Hochachka, P.W. and Somero, G.N. (2002) Biochemical Adaptation: Mechanism and Process in Physiological Evolution. Oxford University Press, Oxford.

[18] Myers, J.B. (1982) Biochemical Response to Change in the Environment and the Nature of "Essential” Hypertension. Medical Hypotheses, 9, 241-257. http://dx.doi.org/10.1016/0306-9877(82)90154-2

[19] Myers, J.B. (2014) The Eco-Society or Eco-Social@ Environment and Heart Disease. A General Systems Approach. PM358. World Heart Federation's World Congress of Cardiology, Melbourne, 4-7 May 2014.

[20] Myers, J.B. (2014) Cognition, Behavior and Brain Function-Ethics of the Mind and General Systems Theory. BIT's 5th Annual World Conference of NeuroTalk-2014, Section 1-8, Nanjing, 16-18 May 2014, 104.

[21] Buchanan, J. and Nettle, J. (2004) Decision. In: Myers vs. the Medical Board of Victoria (VSCA No. 7516).

[22] Australian Council on Healthcare Standards (2013) EQuIPNational. http://www.achs.org.au/publications-resources/equipnational/

[23] MacKee, N. (2013) Make Advanced Care Directives Routine. MJA Insights 44, 18 November. https://www.mja.com.au/insight/2013/44/make-advance-care-plans-routine

[24] Myers vs. Medical Board of Australia (2013) SAT 59.

[25] Myers, J.B. (2010) The Australian Commission on Safety and Quality-Double Standards of Health Care. Internal Medicine Journal, Supplement 1, 275.

[26] Myers, J.B. (2013) Is The Future Direction in Health About Bureaucratic Self Interest or Creativity, Professionalism and Wellbeing? Rights and Responsibility Must Replace Quality and Safety in Health Care. Internal Medicine Journal, 43, 47.

[27] Psalm 27:10. (2001) Tehillim Ohel Yosef Yitzchak. Kehot Publication Society, Brooklyn, New York, 33.

[28] Myers, J.B. (2014) The Cement That Binds Us. Proceedings of 7th Making Cities Liveable Conference, Mantra on Salt Beach, Kingscliff, 10-11 July 2014.

[29] Myers, J.B. (2011) Theoretical and Conceptual Advances. The Backlog of Trees. In: The 1st International One Health Congress, EcoHealth, 7, 1-2. http://dx.doi.org/10.1007/s10393-011-0676-z

[30] Myers, J.B. (2008) Advanced Directive. Choice Based on Informed Consent. Internal Medicine Journal, 38, 455-456. http://dx.doi.org/10.1111/j.1445-5994.2008.01683.x 
Scientific Research Publishing (SCIRP) is one of the largest Open Access journal publishers. It is currently publishing more than 200 open access, online, peer-reviewed journals covering a wide range of academic disciplines. SCIRP serves the worldwide academic communities and contributes to the progress and application of science with its publication.

Other selected journals from SCIRP are listed as below. Submit your manuscript to us via either submit@scirp.org or Online Submission Portal.
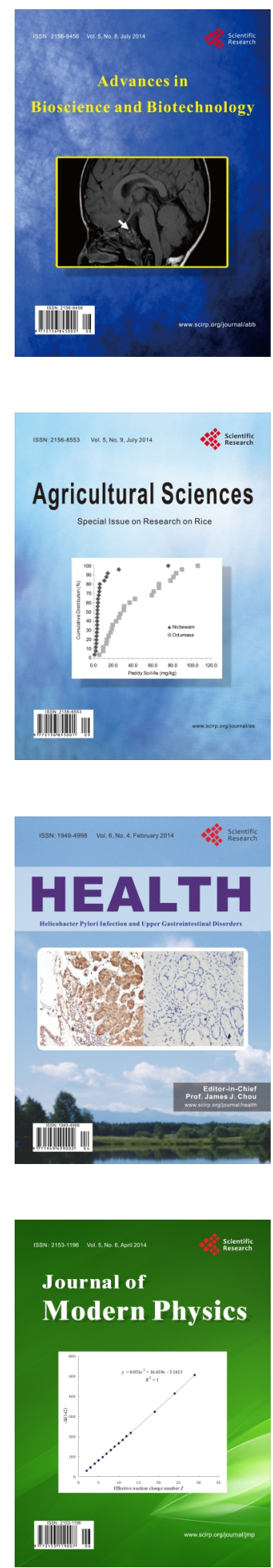
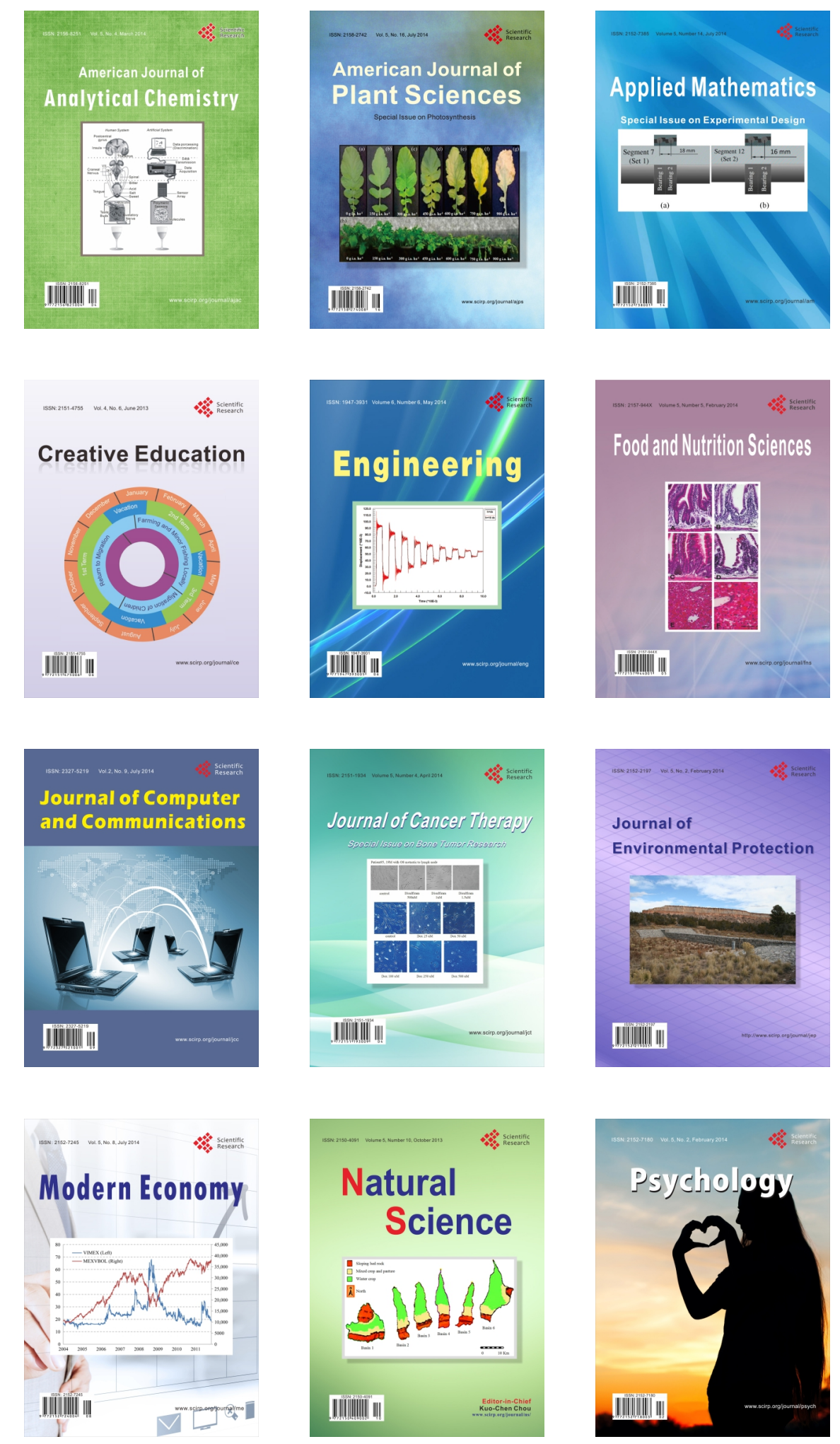